\title{
DIREITOS FUNDAMENTAIS E DESENVOLVIMENTO SUSTENTÁVEL: A IMPORTÂNCIA DA PROTEÇÃO CONTRA DESASTRES HIDROLÓGICOS
}

\author{
FUNDAMENTAL RIGHTS AND SUSTAINABLE DEVELOPMENT: THE \\ IMPORTANCE OF PROTECTION AGAINST HYDROLOGICAL DISASTERS
}

\begin{abstract}
Nilton Carlos de Almeida Coutinho
Doutor em Direito Político e Econômico pela Universidade Presbiteriana Mackenzie. Especialista em Planejamento e gestão pública municipal pela FCT/UNESP. Procurador do Estado de São Paulo, com atuação perante os Tribunais Superiores, em Brasília. Professor junto ao curso de Mestrado em Direito da Universidade Católica de Brasília. Brasília, Distrito Federal, Brasil. nilton.pge@hotmail.com
\end{abstract}

\begin{abstract}
RESUMO
O presente artigo objetiva o estudo do direito de proteção contra desastres dentro da ótica dos direitos sociais e das políticas públicas a eles relacionadas. 0 estudo parte da análise do Estado Democrático de Direito e seu papel na concretização de direitos prestacionais, dentro da teoria dos direitos fundamentais, por meio de pesquisa bibliográfica e documental. São trazidas à discussão questões relacionadas à proteção do meio ambiente e do direito ao desenvolvimento, culminando no denominado desenvolvimento sustentável. A partir daí o texto trata das políticas públicas diretamente relacionadas com a proteção contra desastres hidrológicos. São analisadas a Lei 12.608/2012, que estabeleceu a Política Nacional de Proteção e Defesa Civil, e a Lei 10.257/01, denominada Estatuto da Cidade. Ao final, apresentamse as conclusões acerca da política urbana prevista no Estatuto e sua relação com a proteção ambiental e com o desenvolvimento sustentável, dentro da perspectiva dos direitos fundamentais.
\end{abstract}

Palavras-chave: Direitos fundamentais; Direitos sociais; Política pública; Proteção contra desastres.

\begin{abstract}
This article aims to study the right of protection against disasters from the viewpoint of social rights and public policies related to them. This study starts from the analysis of the Democratic State and its role in achieving rights, within the theory of fundamental rights, through literature and documental research. We brought to discussion issues related to environmental protection and the right to development, culminating in the so-called sustainable development. From there the text addresses public policies directly related to protection against hydrological disasters. We analyzed the Brazilian Law $12.608 / 2012$, which established the National Policy on Protection and Civil Defense, and Law 10.257/01, called the City Statute. At the end, we present the conclusions and about urban policy provided in the Statute and its relation to environmental protection and sustainable development, within the perspective of fundamental rights.
\end{abstract}

Keywords: Fundamental rights; Social rights; Public policy; Protection against disasters. 


\section{SUMÁRIO}

INTRODUÇÃO; 1 OS DESASTRES HIDROLÓGICOS E O PAPEL DO ESTADO; 2 DO DIREITO AO MEIO AMBIENTE E O DIREITO AO DESENVOLVIMENTO SUSTENTÁVEL; 3 POLÍTICAS PÚBLICAS AMBIENTAIS E URBANÍSTICAS E PROTEÇÃO CONTRA DESASTRES: O ESTATUTO DA CIDADE; CONCLUSÃO; REFERÊNCIAS.

\section{INTRODUÇÃO}

Os direitos sociais (subespécie de direitos fundamentais) caracterizam-se como direitos a prestações sociais estatais, como o direito à saúde, o direito à moradia, entre outros. Para ALEXY ${ }^{1}$ "direitos a prestação em sentido estrito" constituem-se como direitos do indivíduo, em face do Estado, a algo que o indivíduo, "se dispusesse de meios financeiros suficientes e se houvesse uma oferta suficiente no mercado, poderia também obter de particulares". Tratam-se, portanto, de direitos que dependem de providências positivas do Poder Público, caracterizandose, assim, como prestações positivas impostas às autoridades públicas. ${ }^{2}$

Neste aspecto, observe-se que o aumento dos desastres decorrentes de eventos climáticos extremos e, em particular eventos relacionados com as águas - inundações, enchentes e alagamentos - conduz à necessidade de adoção e implementação de instrumentos para auxiliar no enfrentamento deste problema, de modo a reduzir as perdas humanas e materiais, decorrentes de tais desastres em uma resposta de adaptação à mudança do clima. Isso porque, a cada dia que passa, aumentam as preocupações da humanidade acerca da proteção do meio ambiente. Tem-se, assim, uma exigência em face do Estado, no sentido de que este assegure o exercício de determinados direitos por meio da implementação de políticas públicas, impondo-se ao Estado uma obrigação de fazer. ${ }^{3}$

Para a proteção contra os desastres hidrológicos, várias são as ações e políticas públicas a serem implementadas pelo Estado. Assim, o administrador público deve agir em diversas áreas, com o apoio de toda a sociedade, a fim de que se possa - de fato - obter-se um desenvolvimento sustentável, protegendo-se o cidadão contra a ocorrência de desastres hidrológicos.

\footnotetext{
${ }^{1}$ ALEXY, Robert. Teoria dos direitos fundamentais. Tradução de Virgílio Afonso da Silva. São Paulo: Malheiros, 2012, p.499

${ }^{2}$ SILVA, José Afonso da. Aplicabilidade das normas constitucionais. 7. ed. São Paulo: Malheiros, 2012, p. 151

${ }^{3}$ COUTINHO, Nilton Carlos de Almeida. Desastres, cidadania e o papel do Estado: as relações entre os direitos fundamentais e a proteção contra desastres "naturais" hidrológicos. Tese (Doutorado em Direito Político e Econômico) - Universidade Presbiteriana Mackenzie, São Paulo, 2014, p. 83
} 
Trata-se de medidas relacionadas a diversas áreas, podendo-se citar questões ambientais e urbanísticas, etc. Nesta seara, ganham destaque a lei 12.608/2012 (a qual estabeleceu a Política Nacional de Proteção e Defesa Civil) e a lei 10.257/01 (Estatuto da cidade), dentre outras.

\section{OS DESASTRES HIDROLÓGICOS E O PAPEL DO ESTADO}

A Constituição Brasileira esclarece que a República Federativa do Brasil constitui-se em Estado Democrático de Direito, o que significa que o Brasil possui uma forma de organização política cuja atuação é determinada e limitada pelo direito. Ou seja: o direito atua como uma forma de limitação do poder estatal, de modo a evitar injustiças, abuso ou desvio de poder.

Consoante ensina Canotilho ${ }^{4}$ o Estado de direito aproximar-se-á de um Estado de justiça no momento em que incorporar em sua estrutura "princípios e valores materiais que permitam aferir do carácter justo ou injusto das leis, da natureza justa ou injusta das instituições e do valor ou desvalor de certos comportamentos".

Dentro desse Estado de Direito encontramos a preocupação com diversos bens jurídicos, cuja tutela precisa ser efetivada de maneira a garantir a dignidade da pessoa humana e os demais direitos fundamentais do indivíduo.

Nesta perspectiva, torna-se possível afirmar que os direitos fundamentais incluem, em uma sociedade de risco, a proteção contra desastres, uma vez que sua ocorrência afeta a dignidade da pessoa humana, uma vez que lhe acarreta danos à saúde, moradia e qualidade de vida. Igualmente, tais desastres comprometem o direito ao meio ambiente ecologicamente equilibrado, além de violar o direito à vida. ${ }^{5}$

Assim, no Brasil, o direito de proteção contra desastres hidrológicos surge como uma nova espécie de direito fundamental e, para o seu adequado estudo enquanto direito fundamental, utilizou-se como matriz teórica a investigação crítica de Flores ${ }^{6}$ o qual, na mesma linha que Bobbio, defende a contínua evolução dos direitos fundamentais em decorrência das

\footnotetext{
${ }^{4}$ CANOTILHO José Joaquim Gomes. Estado de Direito. Fundação Mário Soares Gradiva Publicações, Lisboa,1999, p. 41

${ }^{5}$ COUTINHO, Nilton Carlos de Almeida Coutinho. Da concretização do direito de proteção contra desastres, sob a ótica da teoria dos direitos fundamentais. Revista de Estudos Constitucionais, Hermenêutica e Teoria do Direito. v. 6, n. 2 (2014)

6 FLORES, Joaquín. A reinvenção dos direitos humanos. Trad. Carlos Roberto Diogo Garcia et al. Florianópolis: Fundação Boiteux, 2009, p. 37
} 
necessidades da sociedade. Assim, segundo o referido autor, tais direitos são "resultados sempre provisórios das lutas sociais pela dignidade".

Do mesmo modo, a participação popular ganha maior relevância dentro de um Estado Democrático e de Direito, na medida em que o incentivo à participação popular por meio de mecanismos democráticos (tais como consultas e audiências públicas, debates, exercício do direito de manifestação do pensamento, etc.) traduz-se em um importante aliado na proteção dos direitos fundamentais.

Nesse contexto, surge a necessidade de estímulo à adoção de medidas preventivas em sede de desastres hidrológicos, buscando-se alternativas que possam contribuir para a efetividade do direito de proteção contra desastres, dentro de um Estado Democrático e de Direito.

\section{DO DIREITO AO MEIO AMBIENTE E O DIREITO AO DESENVOLVIMENTO SUSTENTÁVEL}

A Constituição Brasileira de 1988 preocupou-se em inserir em seu texto medidas protetivas com vistas à obtenção de um meio ambiente ecologicamente equilibrado, impondo-se ao Poder Público e à sociedade o dever de defendê-lo e preservá-lo. ${ }^{7}$

Conforme ensinam Silva et. al. $^{8}$ proteger o meio ambiente e o ser humano são os objetivos do desenvolvimento baseado na sustentabilidade, de tal forma que a relação entre os direitos humanos e o desenvolvimento sustentável evidencia a necessidade de proteção e promoção do pleno gozo de todos os direitos humanos e fundamentais, uma vez que, somente assim, poder-se-á atingir o mínimo desejável de justiça social, qualidade de vida, equilíbrio ambiental e desenvolvimento sustentável em nosso planeta. Nessa linha, aliás, Sell e

\footnotetext{
${ }^{7}$ SILVA, Frederico Rodrigues. Políticas públicas do ambiente: um olhar especial acerca da avaliação ambiental estratégica. Revista do Mestrado em Direito da Universidade Católica de Brasília. Brasília, V. 5, $\quad \mathrm{n}^{\circ} \quad 1$, Jan-Jun, 2011.2 Disponível <https://portalrevistas.ucb.br/index.php/rvmd/article/view/2637/1615>. Acesso em: 2 maio 2016.

8 SILVA, Denival Francisco da; ADOLFO, Luiz Gonzaga Silva; CARVALHO, Sonia Aparecida de. Direitos humanos, desenvolvimento sustentável e sustentabilidade. Revista Eletrônica do Curso de Direito da UFSM v. 10, n. 1 / 2015. Disponível em: <www.ufsm.br/revistadireito>. Acesso em: 3 maio 2016
} 
DIREITOS FUNDAMENTAIS E DESENVOLVIMENTO SUSTENTÁVEL: A IMPORTÂNCIA DA PROTEÇÃO CONTRA DESASTRES HIDROLÓGICOS

Hammarströn destacam que o tema sustentabilidade é indissociável da democracia e do humanismo. ${ }^{9}$

Especificamente no Estado brasileiro, observa-se que o meio ambiente passou a ter uma tutela constitucional específica somente na Constituição Federal de 1988, a qual inseriu um capítulo disciplinando o tema. Registre-se, porém, que a questão ambiental vem tratada em diversos outros dispositivos do texto constitucional e em normas infraconstitucionais.

E, para proteger tal direito, nossa Constituição Federal estabeleceu, em seu artigo 225, que:

Todos têm direito ao meio ambiente ecologicamente equilibrado, bem de uso comum do povo e essencial à sadia qualidade de vida, impondo-se ao poder público e à coletividade o dever de defendê-lo e preservá-lo para as presentes e futuras gerações.

Logo, tem-se que a Constituição de 1988 fez muito mais do que simplesmente transformar o meio ambiente em direito constitucionalmente assegurado. Ela o elevou ao status de direito fundamental. E, a partir do momento em que o meio ambiente torna-se um direito fundamental autônomo, políticas públicas específicas começam a ser criadas, trazendo consequências para toda a ordem jurídica. ${ }^{10}$ Logo, observa-se que a constitucionalização do direito ao meio ambiente trouxe importantes transformações para a questão ambiental em nosso país.

Discorrendo a respeito das consequências do seu reconhecimento como direito humano fundamental, Marum ${ }^{11}$ afirma que o direito ao meio ambiente passa a ser irrevogável, eis que passa ele a se constituir como verdadeira cláusula pétrea do regime constitucional brasileiro. 0 mesmo autor ainda destaca a "integração plena e imediata dos pactos, tratados e convenções internacionais que versem sobre o tema", bem como a prevalência da "norma que mais favoreça o direito fundamental ao meio ambiente sadio e equilibrado".

Por outro lado, observa-se que, do mesmo modo que protege o meio ambiente, nossa Constituição Federal também demonstra sua preocupação com o desenvolvimento. Segundo

\footnotetext{
${ }^{9}$ SELL, Cleiton Lixieski; CENSI, Daniel Rubens; HAMMARSTRÖN, Fátima Barasuol. Direitos humanos e meio ambiente: implicações para a sustentabilidade. Revista Eletrônica do Curso de Direito da UFSM v. 9, n. 1 / 2014. Disponível em: <http://www.ufsm.br/revistadireito>. Acesso em: 3 maio 2016.

${ }^{10}$ COUTINHO. Nilton Carlos de Almeida. Políticas públicas ambientais e o Estatuto da Cidade: o urbanismo em um Estado Democrático e de Direito. Revista Argumentum, n 12, Marilia: UNIMAR, 2011 p. 176-177.

11 MARUM, Jorge Alberto de Oliveira. Meio ambiente e direitos humanos. Revista de Direito ambiental. São Paulo: Revista dos Tribunais, 2002, p. 134, p. 134.
} 
estabelece 0 art. $3^{\circ}$ da referida norma fundamental, constituem objetivos fundamentais da República Federativa do Brasil:

I - construir uma sociedade livre, justa e solidária; II - garantir o desenvolvimento nacional; III - erradicar a pobreza e a marginalização e reduzir as desigualdades sociais e regionais; IV - promover o bem de todos, sem preconceitos de origem, raça, sexo, cor, idade e quaisquer outras formas de discriminação.

Assim, o desenvolvimento constitui-se como um dos objetivos fundamentais de nosso Estado Democrático de Direito, de tal forma que deve ser ele incentivado. Contudo, tal desenvolvimento não pode ser protegido a qualquer custo. ${ }^{12}$

A Constituição Federal de 1988, em seu art. 170, estabelece que a ordem econômica estará fundada na valorização do trabalho humano e na livre iniciativa, tendo como objetivo assegurar a todos existência digna, conforme os ditames da justiça social. E, para atingir tais objetivos, surge, não raras vezes, a necessidade de se violar direitos também constitucionalmente protegidos, tais como o direito ao meio ambiente.

Visando conciliar a proteção a esses direitos, surge o que se convencionou denominar de desenvolvimento sustentável. Assim, consoante ensina Sampaio ${ }^{13}$ o desenvolvimento sustentável passa a ser conceituado como o uso racional e equilibrado dos recursos naturais, de forma a atender às necessidades das gerações presentes, sem prejudicar o seu emprego pelas gerações futuras. Surge, aqui, a importância da implementação de políticas públicas ambientais, de modo a permitir que desenvolvimento e meio ambiente consigam coexistir de forma harmônica dentro de nosso ordenamento jurídico. Foi a forma encontrada pela coletividade a fim de tentar minimizar as lesões a esses direitos.

Sobre o tema, registre-se que a Assembleia Geral das Nações Unidas, de 4 de dezembro de 1986, ao proclamar a declaração sobre o direito ao desenvolvimento, estabeleceu que:

1. 0 direito ao desenvolvimento é um direito humano inalienável em virtude do qual toda pessoa humana e todos os povos estão habilitados a participar do desenvolvimento econômico, social, cultural e político, a ele contribuir e dele desfrutar, no qual todos os direitos humanos e liberdades fundamentais possam ser plenamente realizados.

2. O direito humano ao desenvolvimento também implica a plena realização do direito dos povos de autodeterminação que inclui, sujeito às disposições

\footnotetext{
${ }^{12}$ COUTINHO, Nilton Carlos de Almeida. Direito ao meio ambiente: indisponibilidade do bem jurídico e possibilidade de acordos em matéria ambiental. Revista de Estudos Jurídicos da PGE, 2011.

${ }_{13}$ SAMPAIO, José Adércio Leite, et. all. Princípios de direito ambiental. Belo Horizonte: Del Rey, 2003, p. 47.
} 
relevantes de ambos os Pactos Internacionais sobre Direitos Humanos, o exercício de seu direito inalienável de soberania plena sobre todas as suas riquezas e recursos naturais.

Registre-se que a própria declaração de Estocolmo estabeleceu que os recursos não renováveis da Terra devem ser empregados de forma que se evite o perigo de seu futuro esgotamento e se assegure que toda a humanidade compartilhe dos benefícios de sua utilização. Logo, há que se concluir que o direito ao desenvolvimento não possui um fim em si mesmo, devendo pautar-se por diversos outros princípios constitucionais, tais como o da defesa do meio ambiente. Assim, desenvolvimento e proteção ao meio ambiente constituem-se como direitos constitucionalmente garantidos e que devem ser protegidos pelo Estado.

\section{POLÍTICAS PÚBLICAS AMBIENTAIS E URBANÍSTICAS E PROTEÇÃO CONTRA DESASTRES: O ESTATUTO DA CIDADE}

A Constituição Federal de 1988 traz em seu texto expressa menção à proteção ambiental e à política urbana. Segundo estabelece o art. 182 da CF, a política de desenvolvimento urbano (a qual será executada pelo Poder Público municipal, conforme diretrizes gerais fixadas em lei) tem por objetivo ordenar o pleno desenvolvimento das funções sociais da cidade e garantir o bem- estar de seus habitantes.

Neste aspecto, Silva ${ }^{14}$ relembra que "o ambientalismo passou a ser tema de elevada importância nas Constituições mais recentes”. Assim, se no passado não havia uma preocupação dos países com relação à proteção ambiental, hoje encontramos regras explícitas regulamentando tal direito.

No que tange à Constituição Federal de 1988 temos que essa demonstrou sua preocupação com a função social da propriedade urbana, ao estabelecer, em seu art. 182 , $\S 2^{\circ}$ que "a propriedade urbana cumpre sua função social quando atende às exigências fundamentais de ordenação da cidade expressas no plano diretor”.

Assim, o Plano Diretor tem por missão estimular o discurso entre cidadãos e Poder Público, atuando como um mecanismo de interlocução entre ambos. Assim, por meio dele devem

\footnotetext{
${ }^{14}$ SILVA, José Afonso da Silva. Direito Ambiental Constitucional. $3^{\text {a }}$ Ed. São Paulo: Malheiros, 2000, p. 43
} 
as partes deliberar sobre emergências locais, problemas sociais e políticas de crescimento e expansão. $^{15}$

E, para cumprir os objetivos determinados na Carta Magna foi elaborado o Estatuto da Cidade (lei 10.257/01) o qual, além de tratar do uso da propriedade urbana, demonstrou grande preocupação com a questão ambiental, a qual permeia o desenvolvimento sustentável das cidades.

Assim, o Estatuto da Cidade encontra-se inserido dentro de uma política urbana voltada para o desenvolvimento e regularização da propriedade urbana, que será gerida pelo poder público e que contará com a participação da sociedade.

Neste aspecto, ganha destaque o direito ao desenvolvimento, o qual também se constitui como um direito fundamental a ser protegido pelos Estados por meio de políticas públicas eficazes.

0 direito ao desenvolvimento encontra-se inserido nos princípios 3 e 4 da Declaração do Rio de Janeiro/92, in verbis:

PRINCÍPIO 3 - 0 direito ao desenvolvimento deve ser exercido de modo a permitir que sejam atendidas equitativamente as necessidades de gerações presentes $\mathrm{e}$ futuras.

PRINCÍPIO 4 - Para alcançar o desenvolvimento sustentável, a proteção ambiental deve constituir parte integrante do processo de desenvolvimento, e não pode ser considerada isoladamente deste.

Segundo Barral ${ }^{16}$ "desenvolvimento sustentável é o desenvolvimento que responde às necessidades do presente sem comprometer as possibilidades das gerações futuras de satisfazer suas próprias necessidades”. Por isso a importância do planejamento e da elaboração de políticas públicas voltadas para a proteção ambiental. Tais políticas devem levar em conta os objetivos da Administração Pública em benefício da coletividade, sem, contudo, esquecer-se da importância do meio ambiente para a manutenção da vida e da qualidade de vida em nosso planeta.

Com relação à Política Nacional de Proteção e Defesa Civil esta efetivada por meio da lei $\mathrm{n}^{\circ}$ 12.608, de 10 de abril de 2012, a qual tem entre seus objetivos estimular o ordenamento da ocupação do solo urbano e rural, tendo em vista sua conservação e a proteção da vegetação

\footnotetext{
15 SCHENKEL, Schendel Mara. Vulnerabilidade urbana e direitos humanos: uma leitura a partir do desastre de 2008 no Município de Blumenau/SC, Blumenau: UFSC, 2010, p. 48

16 BARRAL, Welber; FERREIRA, Gustavo Assed. Direito ambiental e desenvolvimento. Florianópolis: Fundação Boiteux, 2006, p. 13.
} 
nativa, dos recursos hídricos e da vida humana e combater a ocupação de áreas ambientalmente vulneráveis e de risco e promover a realocação da população residente nessas áreas. (vide art. $5^{\circ}$, X e XI da lei 12.608, de 10 de abril de 2012). Do mesmo modo, tal política nacional abrangerá ações de prevenção, mitigação, preparação, resposta e recuperação voltadas à proteção e Defesa Civil. Neste sentido, a referida lei explicitou o dever da União, dos Estados, do Distrito Federal e dos Municípios no sentido de adotar as medidas necessárias para a redução dos riscos de desastre. Tal dever deriva da natureza de "direito fundamental" inerente à proteção contra desastres e manutenção da dignidade da pessoa humana, o que cria para os entes federados os deveres acima mencionados.

Observe-se, ainda, que um dos objetivos da Política Nacional de Proteção e Defesa Civil é monitorar os eventos meteorológicos, hidrológicos, geológicos, biológicos, nucleares, químicos e outros potencialmente causadores de desastres; e produzir alertas antecipados sobre a possibilidade de ocorrência de desastres naturais. Tal monitoração demonstra a preocupação do poder público em prevenir a ocorrência de desastres em nosso país.

Em sede de políticas públicas relacionadas à proteção contra desastres, observa-se que a ação em diferentes áreas, de forma articulada e envolvendo Poder Público e a coletividade foi a forma preconizada pela lei de Política Nacional de Proteção e Defesa Civil (PNPDEC) para que fossem atingidos os objetivos propostos. Assim, a PNPDEC deverá integrar-se às políticas de ordenamento territorial, desenvolvimento urbano, saúde, meio ambiente, mudanças climáticas, gestão de recursos hídricos, geologia, infraestrutura, educação, ciência e tecnologia e às demais políticas setoriais, tendo em vista a promoção do desenvolvimento sustentável. ${ }^{17}$

Não obstante tenha sido criada uma lei específica atinente à Política Nacional de Proteção e Defesa Civil, tem-se que diversas outras políticas públicas implementadas pelo Poder Público constituem-se como instrumentos que podem ser utilizados na proteção contra desastres “naturais" hidrológicos. Aliás, é justamente por meio da junção e alinhamento de diferentes ações e políticas públicas que a proteção contra desastres poderá ser realizada de maneira eficaz. E tal junção exige planejamento e gestão adequados.

Tais políticas, não obstante tenham objetivos específicos, podem se consubstanciar em instrumentos importantes na proteção e defesa do ser humano contra a ocorrência de desastres, garantindo-se o desenvolvimento sustentável da sociedade e protegendo os direitos fundamentais dos cidadãos. Por exemplo, a Política Nacional de Resíduos Sólidos (instituída por

${ }^{17}$ CARVALHO, Délton Winter de; DAMACENA, Fernanda Dalla Libera. Direito dos desastres. Porto Alegre: Livraria do Advogado, 2013, p. 101. 
DIREITOS FUNDAMENTAIS E DESENVOLVIMENTO SUSTENTÁVEL: A IMPORTÂNCIA DA PROTEÇÃO CONTRA DESASTRES HIDROLÓGICOS

meio da lei 12.305/210) apresenta diretrizes relacionadas à gestão integrada e ao gerenciamento de resíduos sólidos. Neste aspecto, a referida lei tem, dentre seus objetivos, a proteção da saúde pública e da qualidade ambiental e a redução, reutilização, reciclagem e tratamento dos resíduos sólidos. Ocorre que o lançamento de lixo e outros resíduos sólidos em locais inadequados pode causar o entupimento de bueiros, facilitando a ocorrência de enchentes em épocas de chuva, uma vez que a água das chuvas não poderá escoar de forma eficaz. Observa-se, assim, que diversas políticas públicas relacionam-se entre si, contribuindo para o sucesso (ou insucesso) de políticas estabelecidas para outras áreas.

Como parte integrante da política urbana tem-se o Estatuto da Cidade (lei 10.257/2001). Assim, com o objetivo de implementar políticas públicas específicas relacionadas à questão habitacional e de ordenamento territorial foi criada o referido estatuto, o qual regulamenta os artigos 182 e 183 da Constituição Federal, estabelece diretrizes gerais da política urbana e dá outras providências.

Com ele, surge uma nova concepção em relação ao uso, desenvolvimento e ocupação do território urbano, a qual deverá orientar a ação do Poder Público e da sociedade, de modo que a gestão das cidades seja executada por meio de princípios e diretrizes estabelecidos sob a ótica da justiça, democracia e sustentabilidade.

Consoante estabelece o referido estatuto, a Política Nacional do Meio Ambiente tem por objetivo a preservação, melhoria e recuperação da qualidade ambiental propícia à vida, visando assegurar, no País, condições ao desenvolvimento socioeconômico, aos interesses da segurança nacional e à proteção da dignidade da vida humana, atendidos uma série de diretrizes.

Nesta linha, observa-se a presença de uma grande preocupação com a política urbana ambiental no Estatuto da Cidade. Tal Estatuto preocupa-se com a garantia do direito a cidades sustentáveis, bem como o planejamento do desenvolvimento das cidades e da distribuição espacial da população e das atividades econômicas do Município e do território sob sua área de influência. As medidas nele elencadas têm como objetivo evitar e corrigir as distorções do crescimento urbano e seus efeitos negativos sobre o meio ambiente.

Assim, quando o Estatuto fala em sustentabilidade deve esta ser entendida como o direito à terra urbana, à moradia, ao saneamento ambiental, à infraestrutura urbana, ao transporte e aos serviços públicos, ao trabalho e ao lazer, para as presentes e futuras gerações, de tal forma que se torna possível afirmar que a sustentabilidade encontra-se diretamente 
relacionada à necessidade de planejamento e manutenção dos recursos ambientais para as gerações presentes e futuras. ${ }^{18}$

O Estatuto da cidade também apresenta como diretriz a necessidade de ordenação e controle do uso do solo, de forma a evitar a poluição e a degradação ambiental.

As denominadas políticas públicas ambientais têm como ponto principal a garantia do desenvolvimento econômico e social de uma região, sem aniquilar os recursos ambientais nela existentes. Dessa forma, tem-se, no Estatuto da Cidade, a adoção de padrões de produção e consumo de bens e serviços e de expansão urbana compatíveis com os limites da sustentabilidade ambiental, social e econômica do Município e do território sob sua área de influência.

A lei n 12.608, de 10 de abril de 2012, promoveu alterações no Estatuto da Cidade (lei 10.257, de 10 de julho de 2001), de tal forma que o plano diretor passou a ser obrigatório para Municípios localizados em áreas suscetíveis à ocorrência de deslizamentos de grande impacto, inundações bruscas ou processos geológicos ou hidrológicos correlatos. (cf. art. 41, VI da lei 10.257/2001). Neste aspecto, observe-se que o plano diretor é o instrumento básico da política de desenvolvimento e expansão urbana, constituindo-se como parte integrante do processo de planejamento municipal, de tal forma que o plano plurianual, as diretrizes orçamentárias e o orçamento anual devem incorporar as diretrizes e as prioridades contidas no plano diretor.

Dentre as alterações estabelecidas no Estatuto da Cidade, por força da Lei $n^{\circ} 12.608$, de 2012, cite-se, também, a inserção dentre as diretrizes gerais da política urbana, a ordenação e controle do uso do solo, de forma a evitar a exposição da população a riscos de desastres. Assim, com o objetivo de complementar as regras estabelecidas pela Constituição Federal em sede de política urbana, a proteção contra desastres foi expressamente prevista como uma diretriz a ser seguida pela política urbana nacional.

Outra importante mudança inserida no Estatuto da cidade em decorrência da lei $n^{\circ}$ 12.608/2012 refere-se à ampliação dos itens que devem ser incluídos no cadastro nacional de municípios com áreas suscetíveis à ocorrência de deslizamentos de grande impacto, inundações bruscas ou processos geológicos ou hidrológicos correlatos. Assim, nos termos do art. 42-A do Estatuto da cidade, tal cadastro deverá conter:

${ }^{18}$ COUTINHO, Nilton Carlos de Almeida. Direito ao meio ambiente: indisponibilidade do bem jurídico e possibilidade de acordos em matéria ambiental. Revista de Estudos Jurídicos da PGE, 2011 
DIREITOS FUNDAMENTAIS E DESENVOLVIMENTO SUSTENTÁVEL: A IMPORTÂNCIA DA PROTEÇÃO CONTRA DESASTRES HIDROLÓGICOS

I - parâmetros de parcelamento, uso e ocupação do solo, de modo a promover a diversidade de usos e a contribuir para a geração de emprego e renda;

II - mapeamento contendo as áreas suscetíveis à ocorrência de deslizamentos de grande impacto, inundações bruscas ou processos geológicos ou hidrológicos correlatos;

III - planejamento de ações de intervenção preventiva e realocação de população de áreas de risco de desastre;

IV - medidas de drenagem urbana necessárias à prevenção e à mitigação de impactos de desastres;

V - diretrizes para a regularização fundiária de assentamentos urbanos irregulares, se houver, observadas a Lei $n^{0} 11.977$, de 7 de julho de 2009, e demais normas federais e estaduais pertinentes, e previsão de áreas para habitação de interesse social por meio da demarcação de zonas especiais de interesse social e de outros instrumentos de política urbana, onde o uso habitacional for permitido.

Complementando o quanto asseverado, observe-se que, por meio de recente alteração legislativa (lei $\mathrm{n}^{\circ}$ 12.983, de 2014) a identificação e o estabelecimento de diretrizes para a preservação e ocupação das áreas verdes municipais (quando for o caso) com vistas à redução da impermeabilização das cidades também passaram a ser itens constantes no cadastro nacional de municípios com áreas suscetíveis à ocorrência de desastre.

Tal identificação e o mapeamento de áreas de risco levarão em conta as cartas geotécnicas. Igualmente, o conteúdo do plano diretor deverá ser compatível com as disposições insertas nos planos de recursos hídricos, formulados consoante a Lei $n^{\circ} 9.433$, de 8 de janeiro de 1997. Foi a forma que o legislador encontrou para unir diferentes áreas do conhecimento em prol da defesa e proteção do indivíduo que habita em tais áreas.

A lei 12.608/2012 também inseriu um artigo 42-B no Estatuto da Cidade. Segundo estabelece o citado artigo, os Municípios que pretendam ampliar o seu perímetro urbano deverão elaborar projeto específico, o qual deverá ser instituído por lei municipal e atender às diretrizes do plano diretor e deverá conter alguns requisitos mínimos.

Assim, tal projeto deverá conter:

I - demarcação do novo perímetro urbano;

II - delimitação dos trechos com restrições à urbanização e dos trechos sujeitos a controle especial em função de ameaça de desastres naturais;

III - definição de diretrizes específicas e de áreas que serão utilizadas para infraestrutura, sistema viário, equipamentos e instalações públicas, urbanas e sociais;

IV - definição de parâmetros de parcelamento, uso e ocupação do solo, de modo a promover a diversidade de usos e contribuir para a geração de emprego e renda; 
V - a previsão de áreas para habitação de interesse social por meio da demarcação de zonas especiais de interesse social e de outros instrumentos de política urbana, quando o uso habitacional for permitido;

$\mathrm{VI}$ - definição de diretrizes e instrumentos específicos para proteção ambiental e do patrimônio histórico e cultural; e

VII - definição de mecanismos para garantir a justa distribuição dos ônus e benefícios decorrentes do processo de urbanização do território de expansão urbana e a recuperação para a coletividade da valorização imobiliária resultante da ação do poder público.

Deste modo, a aprovação de projetos de parcelamento do solo no novo perímetro urbano ficará condicionada à existência do projeto específico e deverá obedecer às disposições nele constantes.

\section{CONCLUSÃO}

Os desastres naturais (com destaque, para os desastres hidrológicos) têm causado sérios danos para a sociedade, sendo certo que tais desastres têm afetado mais diretamente os moradores das áreas urbanas e, notadamente, as populações mais vulneráveis que vivem em áreas de risco.

Tratando-se de um direito fundamental do indivíduo, de caráter prestacional, a atuação estatal por meio de políticas públicas eficazes é medida crucial para a concretização da proteção contra desastres enquanto direito dessa natureza. Nesta perspectiva, as ações preventivas são, sem dúvida, as que podem trazer maiores benefícios para toda a sociedade, eis que evitam a ocorrência de desastres ou minimizam seus efeitos

Nossa Constituição Federal ampara o direito ao meio ambiente e o direito ao desenvolvimento, de tal forma que ambos devem ser protegidos pelo ordenamento jurídico.

0 meio ambiente constitui-se como um bem de uso comum do povo e essencial à sadia qualidade de vida, de tal forma que o Estado (abrangendo a Administração Pública) não pode se imiscuir da tarefa de protegê-lo. Do mesmo modo, o desenvolvimento deve ocorrer de forma "sustentável", ou seja, respeitando-se os demais direitos fundamentais protegidos pelo ordenamento jurídico. Assim, as políticas públicas ambientais têm como objetivo a defesa do meio ambiente enquanto instrumento de proteção do direito à vida, saúde e qualidade de vida.

Dentro desse contexto, o desenvolvimento de políticas públicas ambientais constitui-se como dever fundamental do Estado e que deve ser realizado de forma coerente. Logo, a adoção de políticas públicas voltadas para a prevenção contra desastres, eliminando (ou mitigando) os 
fatores de risco, é um mecanismo importante para a efetiva proteção do direito fundamental de proteção contra desastres. Assim, o Poder Público investir mais eficientemente em políticas públicas preventivas, o que somente será possível com planejamento e adoção de medidas que impeçam o surgimento (ou agravamento) dos riscos de desastres.

No que se refere aos danos decorrentes de desastres, observa-se que a não regulação antecipada dos riscos pelo direito (e, em especial, pelo direito fundiário, urbanístico e ambiental), tem contribuído para a eclosão de desastres com maior frequência e com consequências de grande magnitude. Do mesmo modo, deve-se incentivar a participação popular na direção, planejamento, controle e avaliação das políticas urbanas, eis que esta se traduz em medida salutar para a gestão democrática das cidades

Em sede de política nacional de proteção e defesa civil, a redução da exposição a riscos, diminuindo a vulnerabilidade de pessoas e bens, a gestão prudente da terra e do meio ambiente e a melhoria dos sistemas de monitoramento e alerta, permitindo-se uma atuação precoce em relação a eventos a adversos, são exemplos de ações voltadas para a redução do risco de desastres, as quais, entretanto, não excluem outras medidas que possam contribuir na proteção deste direito fundamental.

Do mesmo modo, a ampliação dos poderes postos à disposição da Administração Pública com relação à proteção do meio ambiente é imprescindível para que tal função seja realizada de forma eficaz. Assim, para evitar a ocorrência de desastres é necessária uma ação governamental efetiva (por meio de medidas de possibilitem inclusão social, educação, segurança, estímulo à participação comunitária, construção de habitações adequadas e longe de áreas de risco) além de políticas públicas que estimulem o fortalecimento das capacidades locais de enfrentamento dos problemas relacionados aos desastres, criando comunidades resilientes.

Em sede de política urbana, observa-se que o Estatuto da Cidade encontra-se em consonância com a Constituição Federal de 1988, na medida em que demonstra sua preocupação com a questão ambiental, proporcionando à Administração Pública mecanismos que permitam garantir a proteção do meio ambiente, bem como a participação popular nas decisões administrativas.

Do mesmo modo, as alterações implementadas no Estatuto da Cidade por meio da lei 12.608/2012 fizeram com que a proteção contra desastres passasse a estar incluída nas regras constantes do referido Estatuto.

Por fim, o investimento em medidas preventivas, aliadas a uma política ambientalista que tenha como foco a manutenção de um desenvolvimento sustentável, respeitando-se os 
DIREITOS FUNDAMENTAIS E DESENVOLVIMENTO SUSTENTÁVEL: A IMPORTÂNCIA DA PROTEÇÃO CONTRA DESASTRES HIDROLÓGICOS

limites exigidos para a adequada utilização dos recursos naturais e criando-se na população uma consciência ambiental com vistas a evitar que os recursos naturais se tornem escassos e inviabilizem a vida das futuras gerações faz com que esteja-se contribuindo de forma significativa para a tutela do meio ambiente e a proteção contra desastres.

\section{REFERÊNCIAS}

ALEXY, Robert. Teoria dos direitos fundamentais. Tradução de Virgílio Afonso da Silva. São Paulo: Malheiros, 2012.

BARRAL, Welber; FERREIRA, Gustavo Assed. Direito ambiental e desenvolvimento. Florianópolis: Fundação Boiteux, 2006.

BRASIL. Lei $\mathrm{n}^{\circ} 10.257$ de 10 de julho de 2001. Regulamenta os arts. 182 e 183 da Constituição Federal, estabelece diretrizes gerais da política urbana e dá outras providências. Diário Oficial da República Federativa do Brasil, Brasília, DF, 12 set. 1990. Disponível em: <http:// www.planalto.gov.br/ccivil_03/leis/LEIS_2001/L10257.htm> Acesso em: 9 jun. 2016.

BRASIL. Lei no 12.608 de 10 de abril de 2012. Institui a Política Nacional de Proteção e Defesa Civil - PNPDEC; dispõe sobre o Sistema Nacional de Proteção e Defesa Civil - SINPDEC e o Conselho Nacional de Proteção e Defesa Civil - CONPDEC; autoriza a criação de sistema de informações e monitoramento de desastres; altera as Leis nos 12.340, de 10 de dezembro de 2010, 10.257, de 10 de julho de 2001, 6.766, de 19 de dezembro de 1979, 8.239, de 4 de outubro de 1991, e 9.394, de 20 de dezembro de 1996; e dá outras providências. Diário Oficial da República Federativa do Brasil, Brasília, DF, 11 abr. 2012. Disponível em: <http:/ / www.planalto.gov.br/ccivil_03/_Ato2011-2014/2012/Lei/L12608.htm> Acesso em: 9 jun. 2016.

CANOTILHO José Joaquim Gomes. Estado de Direito. Fundação Mário Soares Gradiva Publicações, Lisboa,1999.

CARVALHO, Délton Winter de; DAMACENA, Fernanda Dalla Libera. Direito dos desastres. Porto Alegre: Livraria do Advogado, 2013.

COUTINHO, Nilton Carlos de Almeida. Desastres, cidadania e o papel do Estado: as relações entre os direitos fundamentais e a proteção contra desastres "naturais" hidrológicos. Tese (Doutorado em Direito Político e Econômico) - Universidade Presbiteriana Mackenzie, São Paulo, 2014.

COUTINHO, Nilton Carlos de Almeida Coutinho. Da concretização do direito de proteção contra desastres, sob a ótica da teoria dos direitos fundamentais. Revista de Estudos Constitucionais, Hermenêutica e Teoria do Direito. v. 6, n. 2, 2014. 
COUTINHO, Nilton Carlos de Almeida. Direito ao meio ambiente: indisponibilidade do bem jurídico e possibilidade de acordos em matéria ambiental. Revista de Estudos Jurídicos da PGE, 2011.

COUTINHO. Nilton Carlos de Almeida. Políticas públicas ambientais e o Estatuto da Cidade: o urbanismo em um Estado Democrático e de Direito. Revista Argumentum, n 12, Marilia: UNIMAR, 2011.

FLORES, Joaquín. A reinvenção dos direitos humanos. Trad. Carlos Roberto Diogo Garcia et al. Florianópolis: Fundação Boiteux, 2009.

MARUM, Jorge Alberto de Oliveira. Meio ambiente e direitos humanos. Revista de Direito ambiental. São Paulo: Revista dos Tribunais, 2002.

SAMPAIO, José Adércio Leite, et. al. Princípios de direito ambiental. Belo Horizonte: Del Rey, 2003.

SCHENKEL, Schendel Mara. Vulnerabilidade urbana e direitos humanos: uma leitura a partir do desastre de 2008 no Município de Blumenau/SC, Blumenau: UFSC, 2010.

SELL, Cleiton Lixieski; CENSI, Daniel Rubens; HAMMARSTRÖN, Fátima Barasuol. Direitos humanos e meio ambiente: implicações para a sustentabilidade. Revista Eletrônica do Curso de Direito da UFSM v. 9, n. 1 / 2014. Disponível em: <http://www.ufsm.br/revistadireito> Acesso em 3 mai. 2016.

SILVA, Frederico Rodrigues. Políticas públicas do ambiente: um olhar especial acerca da avaliação ambiental estratégica. Revista do Mestrado em Direito da Universidade Católica de Brasília. Brasília, V. 5, $\mathrm{n}^{\circ}$ 1, Jan-Jun, 2011. Disponível em:

<https://portalrevistas.ucb.br/index.php/rvmd/article/view/2637/1615>. Acesso em 3 maio 2016

SILVA, José Afonso da Silva. Direito Ambiental Constitucional. 3. ed. São Paulo: Malheiros, 2000.

SILVA, José Afonso da. Aplicabilidade das normas constitucionais. 7. ed. São Paulo: Malheiros, 2012. 